\title{
UROLITHIASIS ASSOCIATED WITH TOPIRAMATE
}

\author{
SCOTT EGGENER, SAMUEL C. KIM, HERBERT M. USER, JOSEPH PAZONA, ROBERT B. \\ NADLER
}

Department of Urology, Northwestern University Medical School, Chicago, Illinois, USA

\begin{abstract}
Objective: Topiramate is a sulfamate-substituted monosaccharide anticonvulsant used as adjunctive therapy for intractable refractory seizures. It is report a case of topiramate-induced urolithiasis.

Case Report: A 35-year-old man presented with acute, right-sided, colicky flank pain. He denied hematuria or dysuria. He was in use of phenytoin, risperidone, phenobarbital, and topiramate. The total daily dose of topiramate was $375 \mathrm{mg}$. A CT scan showed a 7 x $1 \mathrm{~mm}$ curvilinear density at the right ureterovesical junction with proximal hydrouretronephrosis. He was managed with rigid ureteroscopic stone extraction and the calculus metabolic analysis revealed the stone was composed of carbonate apatite ( $70 \%)$, calcium oxalate dihydrate $(20 \%)$, and calcium oxalate monohydrate $(10 \%)$.

Comments: The present case typifies many features of topiramate-induced urolithiasis. Those who care for patients with urinary stone disease should be aware of this association.
\end{abstract}

Key words: urolithiasis; acids; metabolism; anticonvulsants; adverse effects

Int Braz J Urol. 2004; 30: 29-31

\section{INTRODUCTION}

Topiramate is a sulfamate-substituted monosaccharide anticonvulsant used as adjunctive therapy for intractable refractory seizures. We report a case of topiramate induced urolithiasis.

\section{CASE REPORT}

A 35-year-old man presented with acute, right-sided, colicky flank pain. He denied hematuria or dysuria. He denied any prior history of stones, was not on a high protein or low carbohydrate (ketogenic) diet, and his family history was noncontributory. Following viral encephalitis at the age of 18 , he developed a seizure disorder that was being treated with phenytoin, risperidone, phenobarbital, and topiramate. The total daily dose of topiramate was $375 \mathrm{mg}$.
He appeared well and had normal vital signs. There was no tenderness to palpation of the abdomen or costovertebral angles. His white blood cell count was $12,100 \mathrm{~mL}$ and serum creatinine was $1.2 \mathrm{mg} / \mathrm{dL}$. Urinalysis revealed a $\mathrm{pH}$ of 7.5 , without hematuria or evidence of infection. A CT scan showed a 7 x 1 $\mathrm{mm}$ curvilinear density at the right ureterovesical junction with proximal hydrouretronephrosis (Figure$1)$.

He was managed initially with intravenous hydration and analgesics. His renal colic continued and the following morning the patient underwent cystoscopy, rigid ureteroscopy, and stone extraction. Small stone fragments were removed from the bladder and the right ureteral orifice without difficulty. A retrograde contrast study showed persistent distal ureteral obstruction, thus rigid ureteroscopy was performed. A tortuous and edematous distal ureter with a persistent stone fragment was encountered and 


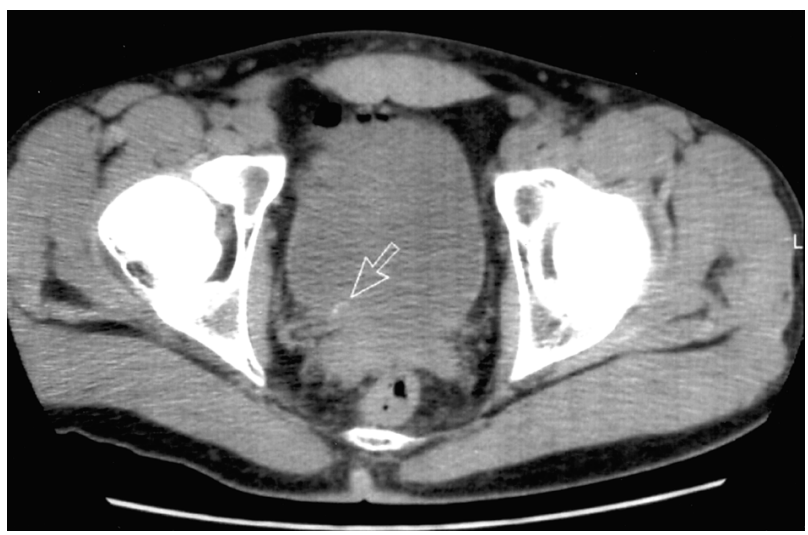

Figure 1 - CT pelvic scan showing a $7 \times 1 \mathrm{~mm}$ curvilinear density at the right ureterovesical junction. There was proximal hydrouretronephrosis (not shown).

attempts at guide wire placement around the stone fragment were unsuccessful. The following day a percutaneous antegrade nephrostogram revealed mild hydronephrosis and narrowing at the right ureterovesical junction. A nephroureteral stent was placed. He was discharged the following day.

Metabolic analysis revealed the stone was composed of carbonate apatite $(70 \%)$, calcium oxalate dihydrate (20\%), and calcium oxalate monohydrate $(10 \%)$.

\section{COMMENTS}

Clinical trials of topiramate reported a $1.5 \%$ incidence of urinary calculi, all occurring in males (1). Apatite, a rare stone associated with alkalosis, was the primary component in 5 of the 7 patients that had a stone analysis. Only $17 \%$ of the stone-forming patients elected to discontinue topiramate. Twelve patients underwent urine studies, all showing hypocitraturia, increased calcium phosphate

\section{EDITORIAL COMMENT}

In the current manuscript, the authors present a case report describing the formation of a carbonate apatite stone caused by an anti-convulsant medication, topiramate. saturation, and no effect on calcium excretion (2). Citrate levels below $100 \mathrm{mg} / 24 \mathrm{~h}$ have been observed in patients on the lowest doses of topiramate (100$300 \mathrm{mg} /$ day). Additionally, in vitro studies of topiramate have demonstrated carbonic anhydrase inhibition (2). The metabolic and clinical effects are similar to acetazolamide, thus it is not surprising that these 2 medications have a similar incidence of urolithiasis (3). Our case typifies many features of topiramate-induced urolithiasis. Those who care for patients with urinary stone disease should be aware of this association.

\section{REFERENCES}

1. Wasserstein AG, Rak I, Reife RA: Nephrolithiasis during treatment with topiramate. Epilepsia. 1995; 36 (suppl 3): 153.

2. Wasserstein AG, Rak I, Reife RA: Investigation of the mechanistic basis for topiramate-associated nephrolithiasis: examination of urine and serum constituents. Epilepsia. 1995; 36 (suppl 3): 153.

3. Kuo RL, Moran ME, Kim DH, Abrahams HM, White MD, Lingeman JE: Topiramate-induced nephrolithiasis. J Endourol. 2002; 16: 229-31.

Received: July 25, 2003

Accepted after revision: October 20, 2003

\author{
Correspondence address: \\ Dr. Robert B. Nadler \\ Department of Urology, Northwestern University \\ Tarry 11-715, 303 E. Chicago Avenue \\ Chicago, Illinois, 60611, USA \\ Fax: + 1312 695-7030 \\ E-mail: rnadler@northwestern.edu
}


animal protein and low in carbohydrates, is a significant risk factor for stones and may have contributed to the stone formation in this particular patient.

\section{References}

1. Kuo RL, Moran ME, Kim DH, Abrahams HM, White MD, Lingeman JE: Topiramate-induced nephrolithiasis. J Endourol. 2002; 16: 229-31.

2. Kossoff EH, Pyzik PL, Furth SL, Hladky HD, Freeman JM, Vining EP: Kidney stones, carbonic anhydrase inhibitors, and the ketogenic diet. Epilepsia. 2002; 43 : 1168-71.
3. Takeoka M, Holmes GL, Thiele E, Bourgeois BF, Helmes SL, Duffy FH et al.: Topiramate and metabolic acidosis in pediatric epilepsy. Epilepsia. 2001; 42: 387-92.

4. Levisohn PM: Safety and tolerability of topiramate in children. J Child Neurol. 2000; 15 (suppl 1): S22S26.

5. Wong IC, Lhatoo SD: Adverse reactions to new anticonvulsant drugs. Drug Safety. 2000; 23: 35-56.

6. Reife R, Pledger G, Wu SC: Topiramate as add-on therapy: pooled analysis of randomized controlled trials in adults. Epilepsia. 2000; 41 (suppl 1) S66-S71.

Dr. Glenn M. Preminger Duke University Medical Center Division of Urologic Surgery Durham, North Caroline, USA 